Conflict of Interest: No conflict of interest was declared by the authors.

Financial Disclosure: The authors declared that this study received no financial support.
2. Iberri DJ, Kwong BY, Stevens LA. Ibrutinib-associated rash: a single centre experience of clinicopathological features and management. Br J Haematol 2018;180:164-166.

3. Lexicomp. Available online at https://online.lexi.com/lco/action/ search?q=ibrutinib\&t=name\&va=ibrutinib.

\title{
References
}

1. Byrd JC, Furman RR, Coutre SE. Targeting BTK with ibrutinib in relapsed chronic lymphocytic leukemia. N Engl J Med 2013;369:32-42.

\section{Ibrutinib-Induced Cardiac Tamponade in Chronic Lymphocytic Leukemia}

\author{
Kronik Lenfositik Lösemide İbrutinib Kaynaklı Kardiyak Tamponad
}

(D) Keisuke Kidoguchi, (D) Yasushi Kubota, (D) Yuki Nishimura, (D) Haruna Kizuka-Sano, (D) Shinya Kimura

Saga University, Department of Internal Medicine, Saga, Japan

\section{To the Editor,}

Acute cardiac tamponade is a rare but fatal disease that requires urgent intervention. The underlying cause of acute cardiac tamponade varies widely [1]. If the pericardial effusion is bloody, the cause is most likely iatrogenic (31\%), a complication of invasive cardiac procedures [2]. Another major common cause is malignancy $(26 \%)$. As a paraneoplastic complication, half of the cases are related to lung cancer; hematologic malignancies are rare (4.8\%) [3]. Both bleeding and atrial fibrillation (AF) are well-known adverse effects of ibrutinib [a Bruton's tyrosine kinase (BTK) inhibitor], but acute cardiac tamponade without concurrent use of antiplatelet or anticoagulant therapy has not been recognized $[4,5]$. This is a case report of cardiac tamponade induced by ibrutinib without concurrent use of antiplatelet or anticoagulant therapy.

A 70-year-old woman with a 12-year history of chronic lymphocytic leukemia (CLL) visited our hospital complaining of malaise and dyspnea. She had not been prescribed antiplatelet or anticoagulant agents. No bleeding diathesis or cardiac disease had been identified. Her initial treatment for CLL was cyclophosphamide monotherapy, which was discontinued because of progression of the disease. The treatment was changed to ibrutinib monotherapy and she achieved partial remission. On admission, she was afebrile, but her respiratory rate was increased to 24 breaths/min and her systolic blood pressure was $96 \mathrm{mmHg}$. On physical examination, jugular vein distention was prominent and heart sounds were muffled. Laboratory tests showed a leukocyte count of 43×109/L with $89 \%$ abnormal lymphocytes, a hemoglobin level of $102 \mathrm{~g} / \mathrm{L}$, and a platelet count of $16.8 \times 10^{9} / \mathrm{L}$. Coagulation tests, including prothrombin time, international normalized ratio (1.09), and partial thromboplastin time (30.4 s), were normal. An electrocardiogram showed AF with low QRS voltage. A chest X-ray showed marked cardiomegaly (Figure 1), which was not apparent 2 months earlier. Transthoracic echocardiography showed a large pericardial effusion with right ventricular collapse, consistent with cardiac tamponade (Figure 1). Emergent pericardiocentesis was performed and $355 \mathrm{~mL}$ of bloody fluid was drained. Fluid analysis findings were as follows: protein, $4.1 \mathrm{~g} / \mathrm{dL}$; lactate dehydrogenase, $2100 \mathrm{U} / \mathrm{L}$; and leukocytes, 4.2×109/L, with $42 \%$ lymphocytes. The lymphocytes were small, with clumped chromatin and scanty cytoplasm (Figure 1). Flow cytometry analysis showed that the lymphocytes were positive for CD5, CD23, and CD19, which was consistent with CLL. Ibrutinib was discontinued and the symptoms resolved without recurrence of $\mathrm{AF}$ or the pericardial effusion.

In this case, cardiac tamponade and AF were ibrutinib-associated adverse events because they improved immediately after ibrutinib discontinuation. The mechanism of bleeding is due to the off- 

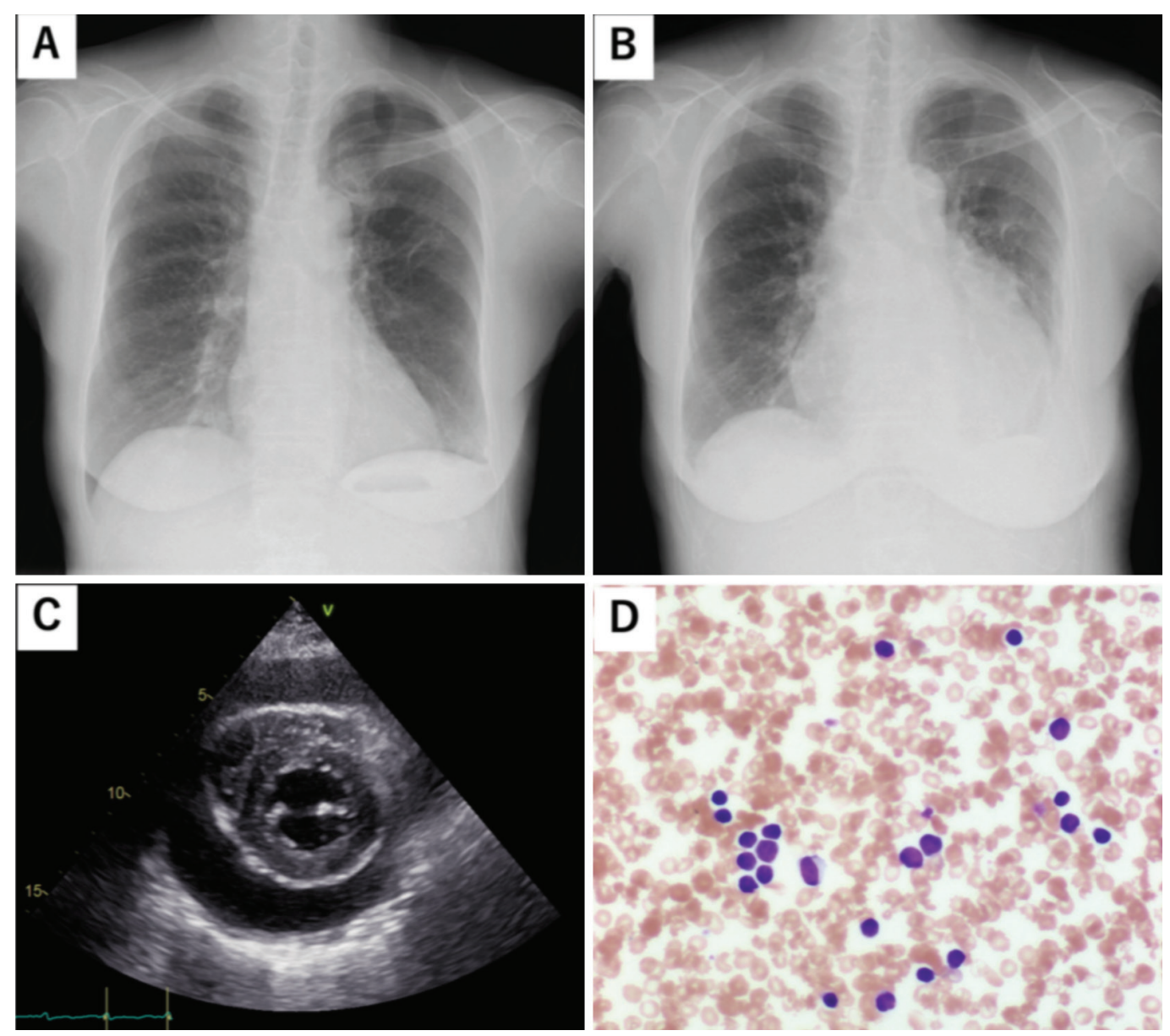

Figure 1. A, B) Chest X-ray revealed marked cardiomegaly (B), which was not apparent 2 months prior (A); C) transthoracic echocardiography showed a large pericardial effusion with right ventricular collapse; D) the drained bloody pericardial effusion contained many CLL cells.

CLL: Chronic lymphocytic leukemia.

target effect of ibrutinib hampering platelet aggregation [6]. Ibrutinib inhibits platelet aggregation in a collagen-mediated manner and is solely dependent on the physiological half-life of platelets (3-4 days) [7]. Ibrutinib irreversibly inhibits BTK, but it has a short half-life $(<3 \mathrm{~h})$. As a consequence, bleeding is considered to be a reversible adverse effect. Although AF and bleeding events are common adverse events associated with ibrutinib, cardiac tamponade is rare. If patients on ibrutinib complain of symptoms such as dyspnea and palpitations, not only AF but also cardiac tamponade should be considered.

Keywords: Ibrutinib, Cardiac tamponade, Bleeding, Atrial fibrillation, CLL

Anahtar Sözcükler: İbrutinib, Kardiyak tamponad, Kanama, Atriyal fibrilasyon, KLL

\section{Ethics}

Informed Consent: Informed consent was obtained from the patient.

\section{Authorship Contributions}

Surgical and Medical Practices: Y.N., H.K-S., Y.K.; Concept: K.K., Y.K., S.K.; Design: K.K., Y.K.; Data Collection or Processing: K.K., Y.K., Y.N., H.K-S.; Analysis or Interpretation: K.K., Y.K., S.K.; Literature Search: K.K.,Y.K.; Writing: K.K., Y.K.

Conflict of Interest: No conflict of interest was declared by the authors.

Financial Disclosure: The authors declared that this study received no financial support.

\section{References}

1. Spodick DH. Acute cardiac tamponade. N Engl J Med 2003;349:684-690.

2. Atar S, Chiu J, Forrester JS, Siegel RJ. Bloody pericardial effusion in patients with cardiac tamponade. Chest 1999;116:1564-1569.

3. Maisch B, Ristic A, Pankuweit S. Evaluation and management of pericardial effusion in patients with neoplastic disease. Prog Cardiovasc Dis 2010;53:157-163.

4. Paydas S. Management of adverse effects/toxicity of ibrutinib. Crit Rev Oncol Hematol 2019;136:56-63. 
5. Miatech J, Hughes JH, McCarty DK, Stagg MP. Ibrutinib-associated cardiac tamponade with concurrent antiplatelet therapy. Case Rep Hematol 2020;2020:4282486.

6. Shatzel JJ, Olson SR, Tao DL, McCarty OJ, Danilov AV, DeLoughery TG. Ibrutinib-associated bleeding; pathogenesis, management, and risk reduction strategies. J Thromb Haemost 2017;15:835-847.
7. Kamel $S$, Horton L, Ysebaert L, Levade M, Burbury K, Tan S, Cole-Sinclair M, Reynolds J, Filshie R, Schischka S, Khot A, Sandhu S, Keating MJ, Nandurkar $H$, Tam CS. Ibrutinib inhibits collagen-mediated but not ADP-mediated platelet aggregation. Leukemia 2015;29:783-787.

\title{
Cutaneous Anaplastic Large-Cell Lymphoma with Dramatic Response to Brentuximab Vedotin
}

\author{
Brentuximab Vedotine Dramatik Yanıtı Kutanöz Anaplastik Büyük Hücreli Lenfoma
}

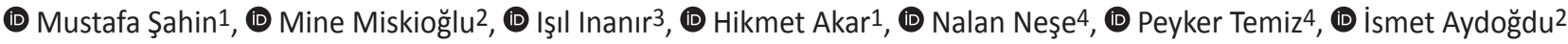 \\ ${ }^{1}$ Celal Bayar University Faculty of Medicine, Department of Internal Medicine, Manisa, Turkey \\ ${ }^{2}$ Celal Bayar University Faculty of Medicine, Department of Hematology, Manisa, Turkey \\ ${ }^{3}$ Celal Bayar University Faculty of Medicine, Department of Dermatology, Manisa, Turkey \\ ${ }^{4}$ Celal Bayar University Faculty of Medicine, Department of Patology, Manisa, Turkey
}

\section{To the Editor,}

Cutaneous lymphomas account for 5\% of non-Hodgkin lymphomas (NHLs). With 75\% of skin lymphomas originating from T-cells, CD30+ anaplastic large-cell NHL (ALCL) is the second most common type after mycosis fungoides. In treatment, excision and radiotherapy are the first options for single lesions, but systemic treatment is required for multiple ones. Brentuximab vedotin (BV) is an antibody-drug conjugate composed of a CD30-directed monoclonal antibody and monomethyl auristatin E. Recently, it has been used in the treatment of Hodgkin lymphoma and chemotherapy-resistant ALCL $[1,2,3]$.

An 84-year-old woman presented to the dermatology department with an erythematous plaque below the right eye, which had been present for 3 months. A round and firm nodule of $5 \mathrm{~cm}$ was also observed on the left breast. The mammography was consistent with a BI-RADS 5 lesion. The histopathological diagnoses were cutaneous ALCL for the facial lesions and invasive ductal carcinoma for the breast nodule. She declined treatment for both.

Three months thereafter, she was admitted with an ulcerative infiltration of the entire right side of the face, invading the right side of the frontal area (Figure 1). She also had weakness and loss of appetite. Hematological and biochemical parameters including lactate dehydrogenase were normal other than hemoglobin of $11.2 \mathrm{~g} / \mathrm{dL}$, and bone marrow biopsy results were normocellular. positron emission tomography-computed tomography (PET/CT) showed involvement of the right side of the face, left breast, and right cervical and mediastinal lymph nodes, with millimetric skin lesions of the whole body, especially in the right femur. The

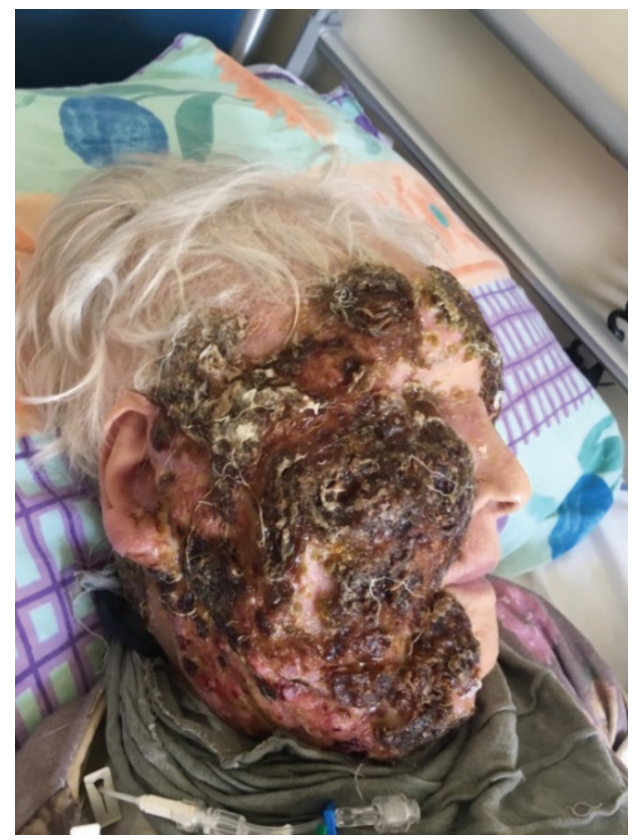

Figure 1. Before treatment. 